\title{
Individual Rights, Good Consequences, and the Theory of Social Choice
}

\author{
Bruce Chapman \\ Version Publisher's version \\ Citation Bruce Chapman, "Individual Rights, Good Consequences, and the \\ (published version) Theory of Social Choice" (1982) 12 Journal for the Theory of Social \\ Behaviour 317.
}

Publisher's Statement This is the peer reviewed version of the following article: Bruce Chapman, "Individual Rights, Good Consequences, and the Theory of Social Choice" (1982) 12 Journal for the Theory of Social Behaviour 317, which has been published in final form at https://doi.org/10.1111/j.1468-5914.1982.tb00454.x This article may be used for non-commercial purposes in accordance with Wiley Terms and Conditions for Self-Archiving.

\section{How to cite TSpace items}

Always cite the published version, so the author(s) will receive recognition through services that track citation counts, e.g. Scopus. If you need to cite the page number of the author manuscript from TSpace because you cannot access the published version, then cite the TSpace version in addition to the published version using the permanent URI (handle) found on the record page.

This article was made openly accessible by $\mathbf{U}$ of 'T Faculty. Please tell us how this access benefits you. Your story matters. 


\section{Individual Rights, Good Consequences, and the Theory of Social Choice*}

\section{BRUCE CHAPMAN}

\section{Introduction}

In a series of recent papers a number of economists and philosophers have been wrestling with the age-old problem of reconciling the value we place on the exercise of individual liberty with the value we also seem to accord to economic efficiency. Amartya $\mathrm{Sen}^{1}$ put the problem in its starkest form when he showed that for some configurations of individual preferences the two following principles are not consistent with one another:

(i) The Pareto Principle: If every individual in society prefers some state of affairs $x$ to another one $y$, then $y$ should not prevail if $x$ is attainable; and

(ii) The Principle of Individual Liberty: For each individual in society there are some "personal" matters such that if the privileged individual prefers, say, $w$ to $z$, then $z$ should not prevail if $w$ is attainable (eg. to sleep on one's back $(w)$ or one's stomach $(z)$, all other things in society being equal).

The purpose of this paper is to view Sen's problem on "the impossibility of the Paretian liberal" from the larger perspective of a general divide which exists in ethics between consequentialist and deontological theories and so demonstrate the source of this inconsistency. In the process I hope to show why economists, and in particular those economists who are the practitioners of the theory of social choice, are committed to a theoretical structure which renders individual rights inconsequential.

Section 2 of this paper summarizes Sen's original theorem. Section 3 discusses the above-mentioned divide in ethics between consequentialism and deontology. Section 4 gives an example, interpreted in Sen's terms, of a situation in which this distinction in ethics may be important. The section also shows that the distinction has important implications for Sen's invocation of the usual collective rationality conditions of social choice theory.

* This paper is a revised version of one presented at the Public Choice Meetings in Charleston, South Carolina in 1979. I am grateful to the participants and in particular to Bruce Ackerman for comments. 
Section 5 anticipates a possible objection to my arguments and attempts an explanation of the nature of a moral dilemma. I finish with some concluding remarks in Section 6.

\section{The Impossibility of a Paretian Liberal}

To illustrate his impossibility theorem Sen asks us to suppose that the book Lady Chatterley's Lover has just been published and that a single copy is available at some public library. There are two individuals in society, namely Prude and Rude, who are contemplating reading the book, and so there are three possible social states (all other things being equal): the social state in which neither individual reads the book (social state 0 ), the social state in which only Prude reads the book $(p)$, and the social state in which only Rude reads the book $(r)$. (Since there is only one copy of the book, it is not possible for both to read it at once.)

Suppose that the two individuals have the following orderings of the three alternative social states. Prude prefers most that no one read the book, but given that someone must read it, he would prefer that he read it rather than Rude, since he can't stand the idea of Rude "gloating over that muck." Thus, Prude's ordering is : op r. Rude considers the social state in which no one reads it to be worst, but agrees with Prude that, if only one individual can read the book, Prude should read it, since Prude will then "be exposed to Lawrence's masterly prose and have his rather narrow literary horizons expanded." Thus, Rude's ordering is: $p r o$.

Now a liberal, concerned for the exercise of free choice, would, according to Sen, choose to assign the pair of social states $(o, p)$ to Prude, since this choice only concerns Prude's reading the book and he should be allowed to make this choice for himself. Similarly, this liberal would assign the rightful pair $(o, r)$ to Rude. Thus, on grounds of individual freedom, since Prude prefers $o$ to $p$ and this preference involves his own rightful domain of choice, $o$ is declared socially preferred to $p$. (Note that this means only that $p$ should not prevail as the social choice if $o$ is attainable; it does not imply that $o$ should actually end up being chosen.) Similarly, since Rude prefers $r$ to $o, r$ is socially preferred to $o$. But $p$ is Pareto-superior to $r$ (and, therefore, socially preferred), and so Sen shows that there is a social preference cycle (viz. 0 preferred to $p, p$ preferred to $r$, and $r$ preferred to 0 ). But acyclicity, the condition that requires that there not be any such social preference cycle, is a necessary condition for a chosen alternative to exist, at least if choice is to accord with our ethical principles. In Sen's example, for instance, if society tries to choose, as it must, any of the three alternatives, $o, p$, or $r$, it will end up choosing so that either some individual's right or the Pareto principle is violated. The question for Sen and others who are troubled by the theorem is which of the seemingly reasonable principles so far proposed (the Pareto 
principle, the liberty principle, or acyclicity) is to be relaxed. The following two sections attempt an answer to that question.

\section{Consequentialism and Deontology}

I begin with a brief discussion of the distinction which as traditionally existed in ethical theory between deontological and consequentialist doctrines. Roughly speaking, consequentialism holds "that the moral value of anything always lies in its consequences and that it is by reference to their consequences that actions, and indeed such things as institutions, laws and practices, are to be justified if they can be justified at all."2 However, as Bernard Williams has remarked, "No one can hold that everything, of whatever category, that has value, has it in virtue of its consequences. If that were so, one would just go on forever, and there would be an obviously hopeless regress."3 So some things must have non-consequential, or intrinsic, value, and Williams takes it "to be the central idea of consequentialism that the only kind of thing that has intrinsic value is states of affairs, and that anything else that has value has it because it conduces to some intrinsically valuable state of affairs." 4

Something of the vagueness of the term "state of affairs" can be overcome if the above view is contrasted with non-consequentialist views, and in particular with the deontological view that actions, as well as states of affairs, have intrinsic value. It is the distinctive mark of consequentialism that it regards the value of actions as derivative only, not intrinsic. That is, the value of an action lies only in its causal properties, or in what sorts of states of affairs the action brings about. For the consequentialist, an act is right because it produces a good state of affairs, or, more precisely, a state of affairs which is better than any other state of affairs accessible to the agent or agents. For the non-consequentialist, or deontologist, it is sometimes at least the other way round. That is, it is important to know how a state of affairs is brought about, and a state of affairs might be thought to be good, or better than any alternative state of affairs, simply because it was brought about by the right sort of act or action.

It is important to clear up a conceptual difficulty about the meaning of such related terms as "state of affairs," "social state" or, perhaps most suggestively, "end state." Contrasting those terms with actions as I have done would seem to imply that a description of a state of affairs cannot include a description of actions, something which would render such terms quite uninteresting, like the stills from a motion picture. In fact, this need not be the case at all. A description of a state of affairs could include a description of actions, a man killed (or killing) rather than a man dead, for example. However, if a state description does include this feature, and it is believed that it is a better state of affairs if there is less rather than more 
killing, then it follows from consequentialism that the right action for an agent is always to bring about that state of affairs with the least killing, even if that means that the agent has to kill an innocent person himself.

This is the fence at which the deontologist often refuses. ${ }^{6}$ There are some things that one ought never to do-such as tell a lie, break a promise, kill an innocent man - even if the balance of advantage favours doing those things, and, moreover, even if the balancing includes the consideration that others tell more lies, break more promises, or kill more people as a conseqence. To think otherwise, the deontologist argues, is to make a nonsense of such things as personal integrity. commitment, responsibility and, most important for our discussion, individual rights and liberties. ${ }^{7}$

Thus, even if we do allow actions to have some intrinsic value we can still distinguish consequentialism. An act is right for the consequentialist because it produces a better state of affairs, descriptions of actions included; but an act is right for the deontologist because it is an act or action of a certain kind. The question of its consequences need not arise at all.

\section{An Example}

The point of the above discussion is best illustrated by way of an example. ${ }^{8}$ Suppose that you find yourself in Nazi-occupied Greece sometime during the Second World War. In the previous week some unknown Greek freedom fighters have ambushed and killed two German soldiers. As the Nazis were wont to do, the local Nazi colonel has rounded up ten innocent villagers and intends to shoot them to deter further such attacks. However, since you are a neutral. and since Hans, the colonel, believes you to be a fine sort of chap, he offers you the choice to kill any one of the villagers yourself and to let the others go free. Of course, if you refuse, then Hans will go ahead and kill them all. The villagers, fully comprehending the situation, are obviously begging you to accept. The relevant questions for our purposes are: what should you do? what rights do you have?

For most people, I think, there is at least some kind of moral dilemma here. In general, we might agree that it is a better world in which there is less rather than more killing of innocent people. So we might be tempted to quickly say that anyone confronted with the above choice should kill one (who would be killed anyway) so that nine others can be saved. Yet at the same time we might feel that one's own killing counts differently from simply killing as such, that we are especially responsible for what we ourselves do rather than for what other people do. More to the point, we might feel that someone in this situation would be acting within his rights to refuse to kill, because he feels killing is wrong, even though this has the consequence that there will be more killing as a result. If this were not so, then we would be running close to the case where a man's own commitments, principles, per- 
sonal integrity or rights had to be surrendered whenever they ran counter to the general interest. That is, we would be operating within a world in which rights were not taken seriously as such, but were merely ornaments adorning essentially consequentialist (perhaps utilitarian) institutions.

There is a related point. It is sometimes argued that an individual, acting in his capacity as a public official, has a duty to act impartially as between individuals whose interests it is the purpose of his office to promote or protect. A senior civil servant should hire or promote the best of the men under him rather than his own son, for instance. Or, in terms of our example, a public official whose duty it is to bring about a world in which there is the least killing of his constituents, has no comparable right of selfindulgence to keep his own hands clean, that is, to avoid his own killing and thus preserve his own moral purity, no matter what happens to the rest of the world. In particular he must always keep a constant eye to achieving good results for his constituents, even if that requires that he undertake an otherwise wrongful action himself. ${ }^{9}$

The importance of these remarks for social choice theory will become clear if we represent the above-described moral dilemma in terms similar to those used in Sen's original exposition on the Pareto-impossible liberal. Let there be three social states: the social state in which no villagers are killed (social state 0 ), the social state in which one villager is killed (social state 1), and the social state in which all ten are killed (social state 10). You, the protagonist, concerned that killing innocent people is wrong, rank the three states of the world in the order 0110 . Hans, the Nazi colonel who proposes that you kill one rather than he kill ten, ranks the alternatives in the order 1100 . That is, it is the worst state of affairs for him that all ten villagers get off, but he is quite happy (indeed, he makes the proposal) that 1 should prevail rather than 10 .

It should be obvious that these individual preference orderings exactly parellel those used in Sen's example about the book Lady Chatterley's Lover (where $o$ has become $0, p$ has become 1 , and $r$ has become 10). Yet, more forcefully than in Sen's original exposition perhaps, we might feel it morally permissible, even obligatory, that the Pareto-inferior alternative 10 , in which all ten villagers are killed, should prevail. We might feel this way because we would be sensitive to an individual's claim that he can't (and shouldn't have to) bring himself to kill an innocent man, even though the consequence, through no fault of his own, is so serious for others.

However, as already suggested, we would not tolerate such a claim from a public official (eg. the mayor of the village) whose duty it was to consider all the alternatives which involved the killing of innocent people, in particular his constituents. For this individual we would expect either state 1 (in which one villager is killed) or state 0 (in which no villager is killed) to be finally chosen, at least if either choice was within the mayor's power to bring about. 
It would not be up to him to claim, as a private individual might, that the final choice of 10 (i.e. ten villagers killed) was not his affair or his responsibility.

This distinction has important and immediate implications for all the collective rationality conditions used in social choice theory in general and in Sen's theorem in particular. To see this, represent the final social choice from the set of attainable alternatives $\{0,1,10\}$ in the usual way as $C\{0,1,10\}$. Let the domains of individual responsibility or choice within such a set be indicated by round brackets. For example, in our original moral dilemma the protagonist had to choose from the pair $(0,1)$, or whether or not he would kill one of the villagers. Thus, in that dilemma the social choice from the set $\{0,1,10\}$, according to a partition of individual responsibility which involves our being sensitive to the protagonist's claim to personal integrity ("it's my killing that counts") is represented as $C\{(0,1), 10\}=\{10\}$. However, if we look to the choice of a public official, such as a village mayor, we would represent his responsibilities in the dilemma as over the pair $(1,10)$. That is, it is the mayor's responsibility to choose whether one or ten of the villagers will end up being killed, not whether or not he will kill one of the villagers himself. Thus, the social choice, given this partition of individual responsibility, is represented as $C\{0,(1,10)\}=\{1\}$.

But, this result, viz., that

(i) $C\{(0,1), 10\}=\{10\}$, and

(ii) $C\{0,(1,10)\}=\{1\}$

directly contradicts a property often imposed on social choice rules which has come to be called path (or partition) independence. Path independence requires that the final social choice from a set of alternatives should be independent of how the alternatives are divided up for consideration, and it is precisely this dependence which is highlighted by the distinction between (i) and (ii) above. ${ }^{10}$ However, we should not be surprised by this. To require that the social choice (here represented by the conjunction of rightful individual choices) from a set of alternatives should be the same regardless of how the alternatives are divided up for (in this case, individual) consideration hardly seems to take that individual rights partition very seriously. It is to make individual rights, quite literally, inconsequential.

$Y e t$ if path independence is violated when we speak seriously of individual rights, then so is the collective rationality condition quasi-transitivity, for that property of the social preference relation implies path independence. (Quasitransitivity requires of social states that if $x$ is socially preferred to $y$, and $y$ is socially preferred to $z$, then $x$ must be socially preferred to $z) .{ }^{11}$ Of course, without quasi-transitivity we cannot have full transitivity either. (Full transitivity requires more strongly that if $x$ is preferred or indifferent to $y$, and $y$ is preferred or indifferent to $z$, then $x$ is preferred or indifferent to $z$ ). Thus, the 
introduction of liberalism into social choice theory is more traumatic than might be thought; it renders suspect the rationality conditions so often used in that theory.

Moreover, if we think it reasonable that the choice from the pair of alternatives $\{1,10\}$, where there is no domain of individual choice, should be $\{1\}$, the Pareto-superior alternative, then we would be violating not only path independence, and hence quasi-transitivity, but the acyclicity of the social preference relation as well. (Acyclicity requires of social states that if $x$ is socially preferred to $y$, and $y$ is socially preferred to $z$, then $z$ is not socially preferred to $x$ ). This is because the choices

(i) $C\{(0,1), 10\}=\{10\}$ and

(iii) $C\{1,10\}=\{1\}$

together violate the Chernoff condition, a condition which partially defines all of the collective rationality conditions in social choice theory, including the weakest one so far discussed, acyclicity. ${ }^{12}$ Again this should not be too surprising since, in terms of the social preference relation, the distinction between quasi-transitivity and acyclicity is rather slight.

I conclude this section, therefore, by saying that the source of the difficulty in Sen's impossibility theorem is neither in his interpretation of liberalism nor in his invocation of the Pareto principle, at least not in particular, but rather in his use of some of the usual collective rationality conditions in social choice theory. ${ }^{13}$ Of course, the collective rationality conditions have the role of linking choices according to the liberty principle with choices according to the Pareto principle and so it seems reasonable that the source of the tension between rightful choices and good overall results should be found here. However, the above arguments have the advantage of suggesting more specifically that the culprit in collective rationality might be the Chernoff condition. I leave my ethical interpretation of what form a violation of that condition might take to another paper. ${ }^{14}$

\section{The Nature of a Moral Dilemma}

It is important to consider at least one objection to representing the above dilemma as I have, that is to say, in terms which run close to Sen's original exposition on the Pareto-impossible liberal. It might be argued that the protagonist in the dilemma does not, in fact, rank the three alternative social states in the order 0110 (i.e. in the order of a decreasing number of killings), but rather that he ranks them 0101 , with the alternative 1 , involving his own killing, as least preferred. After all, it might be said, the protagonist chose not to kill the one even though he knew this would have the result that all ten would be killed. Surely this must mean, on grounds of 
revealed preference, that he considers 1 to be a worse state of affairs than $10^{15}$

There are at least two possible responses to this objection; one comes close to being only a debating point, the other probes more deeply into what it is to have a sound ethical theory. As for the former, it is sufficient to say that a re-ordering of the atlernatives from 0110 to 0101 , so that there is no longer a Pareto-inferior alternative (i.e. all the alternatives are now Pareto optimal), does not affect my essential point, namely, that the collective rationality conditions used in social choice theory are inconsistent with a serious treatment of individual rights. In making this point, the Pareto principle and the particular individual orderings involved need not be mentioned at all. It could still be that, on the one hand, a mayor of the village, who ranked the three alternatives in the order 0101 , but who was responsible to all the villagers so that the rights partition would be represented $\{0$, $(1,10)\}$, would be obligated to choose 1 , and yet on the other hand, our protagonist, whose only commitment is to his own not killing, so that the rights partition is represented $\{(0,1), 10\}$, would be permitted to choose so that 10 was the outcome. Of course, if this were so, both path independence and quasi-transitivity of the social preference relation would be violated. Moreover, if $C\{0,(1,10)\}=\{1\}$ and $C\{(0,1)\}=\{0\}$ (since in the latter choice the horrendous alternative of ten villagers being killed is no longer possible), then the Chernoff condition and, consequently, acyclicity of the social preference relation would also both be violated. Thus, the above objection to my arguments seems to have little force, at least if my only point is to argue against the usual collective rationality conditions in social choice theory.

However, my second response to this kind of objection does speak more directly to the change in the protagonist's ordering of the three alternatives and does seem to involve some more serious misgivings about admitting this kind of objection at all. There is a sense in which by changing the individual ordering from 0110 to 0101 we have changes the problem, or more accurately, avoided the moral dilemma so as to solve it. Surely the point must be that the individual is confronted with a moral dilemma here and that our representation of the situation must somehow capture this tension. Yet by changing the individual ordering from 0110 to 0101 , so that 'my killing the one' is unambiguously a worst alternative for the protagonist, there is no dilemma left. With his preferences diametrically opposed to those of Hans, there can be no sense in which the protagonist is tempted by the offer that the Nazi colonel is making him. On the other hand, if we maintain the ordering 0110 for the protagonist, we preserve the shared preference over the pair of alternatives $(1,10)$, and thus keep intact the idea that there is a potential contract here, a contract which involves the protagonist giving up his commitment against his own killing for the sake of good overall results. 
To preserve the dilemma, therefore, I maintain that we should represent the protagonist's ordering of the three social states as 0110 and indicate his choice not to kill on grounds of personal integrity as a choice of 0 over 1 . Of course, given that choice, Hans will choose to carry on with the execution, that is, he will choose 10 over 0 . And so 10 will prevail as the final result, a state of affairs which the protagonist does consider inferior as an outcome to 1 , but one for which he was not prepared to act as the means to avoiding it. This tension between ends and means, between good results and right actions, is, after all, what the dilemma, and much of moral philosophy, is all about. To come in after the choice is made, brandishing some kind of revealed preference theory as the economist is wont to do, is to come in too late; it is to come in after we have gone through the agony of actually choosing, after we have worked out the moral problem.

One further example should help to reinforce my point against the revealed preference theorist. Suppose that somewhere in the wild, wild west a small platoon of U.S. cavalry has been surrounded by a great number of Apache Indians. Through some kind of mistake the Indians believe that one of the troopers, Jake, has done them a heinous wrong and they want him turned over for summary execution. The troopers themselves are certain of Jake's innocence, since he was playing cards with them on the night in question, but they are unable to convince the Indians of this. The Indians insist that they will massacre the whole platoon if Jake is not turned over, a credible threat due to their great superiority of numbers. Now I would argue that, if the troopers refuse on principle to hand Jake over, the result is clearly Pareto-inferior: ${ }^{16}$ everyone, including Jake (and possibly some Indians) will die, whereas if Jake is handed over only he will die. A revealed preference theorist, on the other hand, might argue that the troopers' refusal to hand Jake over must mean that they prefer that result to any other that was available, that somehow they are 'better off' with that choice. Surely this is an odd argument, since the implication of their choice is their own death, their non-existence. Regardless of what virtuous or altruistic content we pour into their utility functions beyond the concern for mere survival, the fact is that when the troopers are dead they enjoy no utility. To argue that they are somehow better off dead than alive is to argue, for the economist at least, either that they were all suffering from negative utility while alive (perhaps because they were suicidal rather than, as I suspect, principled or heroic), or that they would all suffer from negative utility thereafter were they to live (e.g. the pangs of self-recrimination for not having done their duty), or that the short-lived experience of handing Jake over to the Indians is just so euphoric that it outweighs all their expectations for the utility they might have enjoyed had they acted otherwise and lived to a ripe old age. These interpretations might well save the economist as revealed preference theorist, but surely they impose a severe tax on his credibility. Nor is it possible in this 
instance to invoke some long run welfare criteria and argue that giving in to the Indians now will mean a constant subjection to such threats in the future. As Keynes argued, in the long run we are all dead, and for this platoon which refuses to give in to the Indians' demand, the long run is very short indeed.

\section{Concluding remarks}

In this paper I have tried to suggest, by way of an example and some discussion of two types of ethical theory, that Sen's theorem on the impossibility of the Paretian liberal does highlight certain important difficulties in the theory of social choice. I have argued that the source of logical inconsistency in his theorem is to be found in his use of one of the collective rationality conditions, conditions which tend to render inconsequential any partition of alternative social states into 'protected spheres' of individual free choice. To do this, I would suggest, is not to take rights very seriously.

\section{Bruce Chapman}

Westminster Institute for Ethics and Human Values

Westminster College

London, Canada N6G $2 M 2$

\section{NOTES}

${ }^{1}$ See Sen, Collective Choice and Social Welfare (Edinburgh: Oliver and Boyd, 1970), Chapter 6 and $6^{*}$. For a survey of the recent literature by economists and philosophers, see Sen, 'Liberty, Unanimity and Rights', 43 Economica (1976), 217-45.

${ }^{2}$ Williams, 'A Critique of Utilitarianism', in J. C. Smart and B. A. O. Williams, Utilitarianism: For and Against (Cambridge: Cambridge University Press, 1973), p. 79.

${ }^{3}$ Ibid, p. 82.

${ }^{4}$ Ibid, p. 83.

${ }^{5}$ This last term is Robert Nozick's. The reader may recognize that the distinction between consequentialism and deontology has much in common with the distinction Nozick makes between 'end state' or 'patterned' principles of justice and 'process' principles. See his, Anarchy, State and L'topia (Oxford: Blackwell, 1974), pp. 153-66.

${ }^{6}$ St. Augustine, for example, argued that to lie in order to discover and put an end to the lies of others was not justified. See the discussion in Fried, 'Right and WrongPreliminary Considerations', 5 Joumal of Legal Studies (1976), pp. 193-96. See also Nozick's (supra note 5, pp. 28-30) discussion of the moral impermissibility of violating some rights in order that rights be less violated generally.

7 See Williams, supra note 2, pp. 88-89 and Fried, supra note 6, pp. 175-76.

${ }^{8}$ The following example is a slightly altered version of the dilemma discussed by Williams, supra note 2 , pp. 98-99. With the alterations the dilemma almost exactly corresponds to the one faced by Conchis in John Fowles' novel, The Magus (revised version, 1977) at 429-35. For some interesting historical discussion of this kind of moral problem, see Daube, Collaboration with Tyranny in Rabbinic Law (London: Oxford University Press, 1965). 
${ }^{9}$ See Nagel, 'Ruthlessness in Public Life', in Nagel, Mortal Questions (Cambridge: Cambridge University Press, 1979), pp. 85-86: "the balance of outcome-oriented and action-oriented morality will justify the design of public institutions whose officials can do what would be unsuitable in private life. Some of the deviations will be conspicuously consequentialist : others will express the impersonality of public morality in other ways. Action-oriented constraints will not be absent: there will still be restrictions on means. But those restrictions may be weaker in relation to the results than they are for individuals."

It is not enough to say that the public official has contracted to serve the general interest (although this may be so) and thus given up his right to avoid "dirty hands". To see why this is so it is sufficient to contrast a brother who may have a duty to be impartial among his many brothers, and so may have a duty to kill one to save the many, with a perfect stranger in the same situation who may be at liberty to refuse to kill any of the brothers himself. In neither case does it seem fair to say there is a contract, although in the former there is undoubtedly a more general duty to the "greater good" than in the latter.

"The term "path independence" was introduced into the economics literature by Kenneth Arrow. See his Social Choice and Individual Values (New Haven: Yale University Press, 1963), p. 120. Recently, it has been discussed more fully by Charles Plott, "Path Independence, Rationality and Social Choice", 41 Econometrica (1973), pp. 1079-80: "The process of choosing, from a dynamic point of view, frequently proceeds in a type of 'divide and conquer manner'. The alternatives are 'split up' into smaller sets, a choice is made over each of these sets, the chosen elements are collected, and then a choice is made from them. Path independence, in this case, would mean that the final result would be independent of the way the alternatives were initially divided up for consideration."

${ }^{11}$ For a proof that quasi-transitivity of the social preference relation implies path independence, see Blair et al "Impossibility Theorems without Collective Rationality", 13 Journal of Economic Theory (1976), 361-79.

12 The Chernoff condition requires that if some alternatives are chosen from a superset, and then the superset is narrowed down to a subset which still contains some previously chosen alternatives, then none of the previously chosen alternatives should be rejected in a choice from that subset. For proofs that the Chernoff condition helps to define all of the collective rationality conditions so far discussed, see Blair et al, supra note 11 .

${ }^{13}$ In fact, the proposed change in the collective rationality conditions will change the appearance of the Pareto principle and Sen's liberty principle as a consequence. What is unchoosable according to those principles in some sets, say pairs, may be choosable in other larger sets if collective rationality is relaxed. This obviously violates the two principles as Sen interprets them since under his interpretation inferior alternatives according to the principles cannot be chosen in any set. This should explain why in a recent discussion of Sen's theorem, in which the rationality properties are relaxed, John Ferejohn shows that the method of social choice will sometimes have to choose a Pareto-inferior alternative. See his paper "The Distribution of Rights in Society" in Gottinger and Leinfeller (eds.) Decision Theory and Social Ethics (Dordrecht, Holland: D. Reidel Publishing Company, 1978).

${ }^{14}$ For some suggestions that a relaxation of the Chernoff condition in social choice theory may be required if one wants to have a hierarchical (or constitutional) structure of choices, see Chapman "Individual Rights and Collective Rationality: Some Implications for Economic Analysis of Law", 10 Hofstra Law Review (1982), especially pp. 470-75. Also see Chapman "Rights As Constraints: Nozick versus Sen" 
Theory and Decision (forthcoming) for an argument which relates a relaxation of collective rationality conditions to the work of Robert Nozick.

is I am grateful to Burton Weisbrod for stressing to me the importance of considering this objection. I hope that he finds some kind of satisfaction in my responses to it.

${ }_{16}$ The violation here is of the strong Pareto principle rather than the weak: Jake is indifferent between the two outcomes involving his death, whereas all others consider the outcome in which they die to be inferior. On the difference between the strong and weak Pareto principle, see Sen, Collective Choice, supra note 1, Chapter 2. For some indication that this is indeed how an economist would interpret this dilemma, see Posner "Utilitarianism, Economics, and Legal Theory" 8 Journal of Legal Studies (1979), pp. 117-18. 